\title{
What Is the Value of Obesity Research? - Comment on Blundell JE, Hebebrand J, Oppert JM. What is the value of obesity research? Obes Facts 2010;3:279-282.
}

\author{
Tommy L.S. Visscher ${ }^{a}$ Mary Nicolaou ${ }^{b}$ Wilrike J. Pasman ${ }^{c}$ Gijs H. Goossens ${ }^{d}$ \\ Edgar G.A.H. van Mile Mieke C. van Spanje ${ }^{\text {f }}$ Edwin C.M. Mariman ${ }^{d}$ \\ a Research Centre for the Prevention of Overweight Zwolle, Windesheim University of Applied \\ Sciences, Vrije Universiteit and VU medical centre, Zwolle, ${ }^{b}$ Department of Public Health, AMC, \\ University of Amsterdam, Amsterdam, ' Pharmacokinetics \& Human Studies, TNO, Zeist, d NUTRIM \\ School for Nutrition, Toxicology and Metabolism, Department of Human Biology, Maastricht \\ University Medical Center, Maastricht, e Department of Paediatrics, Jeroen Bosch Medical Centre, \\ 's-Hertogenbosch, The Netherlands Obesity Society, Wychen, the Netherlands
}

\section{Introduction}

In a critical, honest, and strong review on the value of obesity research within Europe, the European Association for the Study of Obesity's Scientific Advisory Board (EASO-SAB) has shared their thoughts on obesity research that has been performed since the establishment of the Association in 1986 [1]. It is important that scientific associations perform such self-evaluations, in order to put forward future directions of research, and it is to be appreciated that this self-evaluation did not end up as a 'celebration' regarding own performances. Instead, pessimistic readers could detect a rather disappointing view of obesity research, culminating in the observation that not much useful has come out to help halting the obesity epidemic. However, more optimistic readers may conclude that the obesity research in Europe has been doing quite well on multiple aspects of obesity, since research findings have led to new hypotheses and, therefore, more possibilities to combat obesity. The purpose of the EASO-SAB review was to stimulate reflection and to initiate a continuous dialogue with its members. In this commentary, we aim at answering the question 'What is the value of obesity research?', and at discussing 'How to put forward the value of obesity research?' In other words: what can we learn from the way obesity research has been conducted until now, and how are we going to benefit from that knowledge in the near future?

The members of the Board of The Netherlands Association for the Study of Obesity (NASO) have read and discussed the EASO-SAB review [1] with great interest. We forwarded EASO's invitation to respond to the synopsis to our members by e-mail, and obtained 
responses from members representing various disciplines within obesity research, ranging from genetics and human tissue metabolism to public health and prevention, and from clinicians' to patients' perspectives.

The review by the EASO-SAB confronts us with the fact that what we are studying is much more complex than what we may originally have anticipated. In fact, we have just scratched the surface of the iceberg of useful knowledge. The obesity epidemic has increased more rapidly than research could provide solutions and, at the same time, has generated new problems such as weight cycling instead of primary weight gain [2] and the influence on chronobiology by an altered sleeping pattern [3].

We discovered two main themes being important for future development of obesity research in order to be relevant for science and society, namely i) a stronger focus on integrated systems thinking and, ii) a more translational approach of obesity research.

\section{Integrated Systems Thinking}

There is a need for integrated systems thinking. Obesity is not a single genetic, physiological, behavioural or psychological condition $[4,5]$, and thus needs to be addressed and understood as an interaction between all these and several other aspects [6].

Integrated systems thinking would imply, for example, more attention to what people normally eat and more attention to effects of complete meals, rather than focusing on specific food components [7,8]. Although the effect of each macronutrient is important, food intake regulation and the physiological response to food intake is based on interaction between different macronutrients and of overall diet quantity as well as quality [9]. Taking the whole system into account would reduce the emphasis on single food components (e.g. glycemic index or cholesterol) which in turn may contribute to a reduction in misleading marketing by the food industry. Integrated systems thinking also implies that a whole range of behavioural and socio-cultural influences on food intake should be accounted for. For example, the influence of meal size on eating behaviour [10] or the role of the socio-cultural environment on what is eaten and why [11].

The increasing focus on chronic disease management in current practice is in line with the plea for a broader vision and reason to study obesity more in relation to other diseases. We all seem to agree that we want to prevent and treat (the consequences of) obesity, since obesity poses a major impact on our society $[12,13]$. It is therefore that at least part of our research should have a broader focus than obesity alone. From obesity physiology, we have learned that many organs play a role in the development of obesity and the detrimental physiological consequences of an excessive fat mass. Rather than prioritizing organs of interest and focussing on just one organ, we may better focus on the clarification of pathophysiologic mechanisms in various organs and inter-organ cross-talk in obesity, and then integrate this knowledge to design intervention strategies to reverse the consequences of obesity at the whole-body level. The focus on inter-organ cross-talk certainly is a promising step forward, as we have learned during the European Congress on Obesity in Istanbul (2011) and as we will experience during the upcoming European Congresses on Obesity in Lyon (2012) and Liverpool (2013). At the genetic level, our focus has to move from a few genetic mechanisms that are uncommon in our human population to mechanistic links between gene polymorphisms and energy balance incorporating the general basis of geneenvironment interactions in our studies [14]. Also here, chances are to be recognized and developed regarding applied systems thinking.

Clinically, in terms of therapeutic progress, we may have to separate control of energy balance from the area of (metabolic) complications of obesity. In particular, it seems a lot 
more complicated to adjust energy balance than to treat or prevent complications in obese individuals. The SAB report tends to label interventions leading to a weight loss of 3.5-6.0 $\mathrm{kg}$ as rather disappointing. Optimistic readers may argue that weight loss of 'only' $3.5 \mathrm{~kg}$ in persons with body height of $1.80 \mathrm{~m}$, and weight of $90 \mathrm{~kg}$, already resembles an 'impressive' $28 \%$ reduction of this person's overweight. These readers are likely to be correct to be optimistic about such weight losses. It is now commonly accepted that weight loss of about $5 \%$ of initial body weight has substantial beneficial metabolic effects [15-19]. Indeed, in the case of the Diabetes Prevention Program (DPP), weight loss of about $3.5 \mathrm{~kg}$ was associated with a $58 \%$ reduction in the development of type 2 diabetes [20].

Also, the distinction between exercise, physical activity and sedentary behaviour hints more towards a sense of integrated systems thinking. We do not fully agree with the authors' statement [1] that an amount of physical activity that would be tolerable and enjoyable would hardly be effective. In this case, it is important to emphasise that physical activity, rather than physical exercise per se, contributes more to total daily energy expenditure. Daily and moderately intense activities contribute more to total energy expenditure than do highly intense activities [21], and sedentary behaviour should not be confused with low levels of overall activity. Hence, highly prevalent sedentary behaviours, such as TV viewing, may well be able to occur within a physically active life-style [22], although associations of sedentary behaviour with activity level may differ between countries with different activity levels [23]. We do agree that there is much to learn regarding the optimal conditions to promote exercise and engage people in daily-life physical activities and to reduce sedentary behaviour. Future studies should not only include the impact on body weight as a single issue but also include the impact on related health indicators, multiple physiological pathways and the impact on social indicators, such as 'participation in society' are important topics for future studies.

Perhaps, another example of integrating systems thinking that is discussed in the EASO-SAB report is the role of surgery in obesity research [24, 25]. The assessment of surgical interventions could well reveal causes and consequences of obesity. It may not only be a solution at an individual level (the morbidly obese patient), but can also contribute to our understanding of pathophysiologic mechanisms. This, in turn, would provide valuable new insights that may add to information obtained from epidemiological studies. In addition, the physiological effects of surgery may open alleys for the design of life-style interventions and pharmacological agents to treat obesity and associated metabolic complications.

As discussed in the EASO-SAB report, animal models are potentially important but should be interpreted with caution, which is even more true when considered from a more systems thinking approach. Furthermore, a stronger focus on the consequences of obesity is needed. In fact, human studies provide evidence that physiological processes in animal studies are not always operational in humans [26, 27]. For example, certain interventions may even have completely opposite effects in humans compared with rodents due to differences in physiology and evolutionary adaptation (e.g. different expression of receptor subtypes). The SAB already hinted that there appears to be a mismatch between animal and human research; commonly, animal studies focus on adipose tissue development (on a high-fat diet), whereas in humans the focus is more on already developed tissue (once a person has become obese). A second issue of concern is that obesity in animal models appears to be driven by an overload of energy, not by reduced physical activity levels. On the other hand, adipose tissue research in animals (e.g. fat transplantation experiments) has provided valuable insight into the role of adipose tissue dysfunction, rather than adipose tissue mass per se, in the pathophysiology of obesity-related complications [28]. We know from literature that the consequences of over-feeding differ from those of reduced physical activity levels. Thus, although animal studies certainly provide complementary information, we would strongly recommend further investment in human obesity research. 
There is broad consensus that obesity is a high-priority public health issue $[12,13]$. It is important, therefore, to consider the broad scope of public health itself when thinking about obesity [4]. We need to broaden our thinking and include consideration for the links between obesity and issues such as the impact of globalisation [29] and economic development as well as the impact of modern life-styles on the environment (global warming and food production [30]), and global social inequalities [31]. Such issues question the foundations of modern society. Research in these areas may well lead to insights on how to motivate individuals and communities. Are there places in the world where social movements are responding to these issues? What are they doing, why, and what are the outcomes? In many places, these concerns are a luxury afforded to those beyond the need to struggle for daily survival. Is it realistic to think that we can bring these issues to people that are struggling to obtain the basic needs to survive? More research into the extent of these interrelationships is needed.

\section{Translational Obesity Research}

We appreciate the plea by the EASO-SAB for a more translational approach in obesity research, following a popular stream in public health research [1]. A focus shift should direct obesity research more into the direction of translational research and implementation issues, in order to enhance the applicability of study outcomes and in order to better serve prevention and management efforts with our research [32,33]. With combined effort from different disciplines within the field of obesity research, the available knowledge may be translated more adequately to enhance the availability of prevention and treatment programmes that are being implemented among a larger part of the population in need and sustained for longer periods of time [34].

Communities and patients are of extreme importance in prevention and treatment research. Individual responsibility for health behaviour has become increasingly important, a message communicated heavily in 'right-wing' countries. Obviously, patients with overweight and obesity do need help to take their responsibility. We very much support the suggestion [1] that 'research is needed into ways to empower people to engage in activities [34], and in constructing an environment (physical and socio-cultural) that enables people to make healthy choices and prevents people from being lured into unhealthy behavioural patterns' $[35,36]$. Techniques such as shared decision making, may well be of utmost importance in order to give the patients a voice [37]. Likelihood of success is much higher when consensus is based on mutual input. Perhaps these are one of the most crucial issues in obesity treatment to invest in during the next decade.

In order to understand and respond appropriately to the need of society and of policy makers, we should think about questions such as 'What do we consider normal?'. Avoidance of stigmatisation is paramount in our communications; this implies that we should abstain from labelling obesity as a state 'deviant from normal'. Interestingly, even the WHO growth reference curves for children's BMI distribution are skewed to the right [38], meaning that more children are on the right than on the left end spectrum of the body weight distribution. In fact, due to large changes in society $[4,35]$, it becomes increasingly challenging to define the range of a 'normal' BMI. Concurrent to our plea to regard obesity more in relation to other chronic diseases, we may have to shift our reference categories from normal weight to 'non-elevated risk for obesity complications [39,40],' also bearing in mind that about $25 \%$ of obese subjects are 'metabolically healthy' [41]. In this respect, existing research and policy principles as DALYs (disability-adjusted life years) and QUALYs (quality-adjusted life years) could well be used as a start. 
When communicating with policy makers and the population of interest, we need to be more clear about the consequences of obesity and the different chronic conditions that accumulate in obese persons, most particularly during the last decades of individuals' lifespan [42-44]. It is important to understand that the impact of obesity differs from the impact of smoking behaviour for instance. While the impact of smoking is explained by increased mortality, the impact of obesity is explained by an increased number of unhealthy life years with chronic diseases and disabilities [13,44]. This discussion has consequences for our health care system and fiscal policies (like the fat tax on food items; insurance fee for obese subjects etc.). We still have to increase society's and policy makers' knowledge and awareness regarding the importance of obesity.

The EASO-SAB report tends to suggest that, although cognitive models can describe processes, they have failed to achieve change, and the report questions whether behavioural change requires political will rather than more research. The political will required to change the system in which we function so that we are able to collectively achieve behavioural change, is indeed tremendous, but lacking [45], and undermined by competing interests, including the interest to maintain economies and the current status quo. For example, in the last year the Dutch government rejected a plea for a ban on nutritional marketing towards children, based on evidence that parents have a role in educating health behaviour although there is compelling evidence that marketers' influence on behaviour is much stronger than that of parents [46]. This can be largely explained by the considerable investments by industry, both financially as well as in terms of expertise. Until we are successful in increasing the political will to stimulate health behaviour, we cannot abandon our focus on helping individuals deal with the environment as it is. Continuing research in understanding and guiding behavioural change remains important [34, 36]. Marketing tools derived from industry may provide new tools in seducing the individuals towards behavioural changes $[47,48]$.

Enabling and empowering communities and patients to make healthy choices, as important public health issue, is closely linked to the question of whether we need more research or more socio-economic analyses. The answer to this question is, however, not clear cut. A focus on socio-economic analysis implies that we understand the mechanisms underlying the socio-economic differences, which is far from true. During the EASO Prevention Task Force satellite meeting in Stockholm (2010) and EASO's mini-symposium during the ECO 2011, it was concluded that we still need more information regarding the role of socio-economic status (SES) and its interaction with socio-cultural issues in causing obesity [49]. Therefore, it seems that there is another layer of complexity on the SES-obesity issue that we need to further understand.

\section{Continued Importance of the Individual}

There is one last question posted in the EASO-SAB report that we would like to respond to, namely the question 'When to intervene? In the early phase of weight gain (an overweight period) or only after frank obesity has developed?' It seems that we need to intervene all along the spectrum of this epidemic, including prevention of overweight/obesity. Thus, while we need to prevent obesity, we should not abandon those that are overweight or obese. Especially in the latter group of subjects, small changes in body weight may have a substantial beneficial impact on health, as discussed before. The establishment of multidisciplinary personalised obesity centres, where subjects receive tailor-made guidance, are needed in order to put forward and further guide obesity research.

When studying applicability of prevention and management efforts, safety issues are very important when evaluating obesity interventions, which especially holds true for phar- 
macological treatments and surgery. Safety should not only include physical safety but also 'psychological safety.' When studying the effects of swimming, for example, it is important to study whether the reduction of chronic disease risk factors weighs up against the potential risk of being made ridiculous during swimming sessions.

In order to become more successful in halting the obesity epidemic, we need to perform our future studies on implementation and evaluation by making use of a greater interaction with policy makers, health professionals in the field and our target populations in order to reach larger parts of the population in need and in order to improve long-term successes [34, 50].

\section{Conclusions}

We understand well that due to a lack of (financial) resources, choices have to be made regarding funding of obesity research. The EASO-SAB report [1] and this commentary may serve as a basis for such choices. The work of the EASO since 1986 has clearly shown that there is no time for hesitation but it is time for further action. We have to continue with what we have started many years ago and, at the same time, attack new problems and research questions. This should be done within a broader concept, using integrated systems thinking and a more translational approach.

\section{References}

1 Blundell JE, Hebebrand J, Oppert JM: What is the value of obesity research? Obes Facts 2010;3:279-282.

- 2 Cereda E, Malavazos AE, Caccialanza R, Rondanelli M, Fatati G, Barichella M: Weight cycling is associated with body weight excess and abdominal fat accumulation: A cross-sectional study. Clin Nutr 2011;30:7187232.

3 Garaulet M, Ordovás JM, Madrid JA: The chronobiology, etiology and pathophysiology of obesity. Int J Obes 2010;34:1667-1683.

- 4 Kumanyika S. Minisymposium on obesity: overview and some strategic considerations. Annu Rev Public Health 2001;22:293-308.

5 Butland B, Jebb S, Kopelman P, et al. Fore sight Tackling Obesities: Future Choices - Project Report. www.bis. gov.uk/assets/bispartners/foresight/docs/obesity/17.pdf(assessed September 2011).

- 6 Rutter H. Where next for obesity? Lancet 2011;378:746-747.

- 7 Crepinsek MK, Gordon AR, McKinney PM, Condon EM, Wilson A: Meals offered and served in US public schools: do they meet nutrient standards? J Am Diet Assoc 2009;109(2 suppl):S31-43.

8 Economos CD, Folta SC, Goldberg J, Hudson D, Collins J, Baker Z, Lawson E, Nelson M: A community-based restaurant initiative to increase availability of healthy menu options in Somerville, Massachusetts: Shape Up Somerville. Prev Chronic Dis 2009;6:A102.

- 9 Kant AK: Indexes of overall diet quality: a review. J Am Diet Assoc 1996;96:785-791.

10 Fay SH, Ferriday D, Hinton EC, Shakeshaft NG, Rogers PJ, Brunstrom JM: What determines real-world meal size? Evidence for pre-meal planning. Appetite 2011;56:284-289.

-11 Nicolaou M, Doak CM, van Dam RM, Brug J, Stronks K, Seidell JC: Cultural and social influences on food consumption in Dutch residents of Turkish and Moroccan origin: a qualitative study. J. Nutr Educ Behav 2009;41:232-241.

12 Haslam DW, James WPT: Obesity. Lancet 2005;366:1197-1209.

13 Visscher TLS, Seidell JC: The public health impact of obesity. Annu Rev Public Health. 2001;22:355-375.

14 Dobrin R, Zhu J, Molony C, et al: Multi-tissue coexpression networks reveal unexpected subnetworks associated with disease. Genome Biol 2009;10:R55.

15 National Institute of Clinical Excellence (NICE): Obesity: Guidance on the Prevention, Identification, Assessment and Management of Overweight and Obesity in Adults and Children. 2006. www.nice.org.uk/ nicemedia/pdf/CG43NICEGuideline.pdf(last accessed April 16, 2012).

16 Wing RR, Jeffery RW, Burton LR, Thorson C, Kuller LH, Folsom AR: Change in waist-hip ratio with weight loss and its association with change in cardiovascular risk factors. Am J Clin Nutr 1992;55:1086-1092.

17 Blackburn G: Effect of degree of weight loss on health benefits. Obes Res 1995;3(suppl 2):211s-216s. 
Visscher et al.: What Is the Value of Obesity Research? - Comment on Blundell JE, Hebebrand J, Oppert JM. What is the value of obesity research? Obes Facts 2010:3:279-282.

18 Goldstein DJ: Beneficial health effects of modest weight loss. Int J Obes 192;16:397-415.

19 Zelissen PMJ, Mathus-Vliegen: Behandeling van overgewicht en obesitas bij volwassenen: voorstel voor een richtlijn (in Dutch). Ned Tijdschr Geneeskd 2004;148:2060-2066.

-20 Tuomilehto J, Lindström J, Eriksson JG, et al: Prevention of type 2 diabetes mellitus by changes in lifestyle among subjects with impaired glucose tolerance. N Engl J Med 2001;344:1343-1350.

21 Westerterp KR: Pattern and intensity of physical activity. Nature 2001;410:539.

22 Biddle SJH, Marshall SJ, Gorely T: Temporal and environmental patterns of sedentary and active behaviors during adolescents' leisure time. Int J Behav Med 2009;16:278-286.

-23 Melkevik 0, Torsheim T, Iannotti RJ, Wold B: Is spending time in screen-based sedentary behaviors associated with less physical activity: a cross national investigation. Int J Behav Nutr Phys Act 2010;7:46.

$\$ 24$ Fried M, Hainer, Basdevant A, et al: Interdisciplinary European guidelines on surgery of severe obesity. Obes Facts 2008;1:52-59.

25 Buchwald H, Avidor Y, Braunwald E, et al: Bariatric surgery: a systematic review and meta-analysis. JAMA 2004;292:1724-1737.

26 Mestas J, Hughes CCW: Of mice and not men: differences between mouse and human immunology. J Immunol 2004;172:2731-2738.

27 Emes RD, Goodstadt L, Winter EE, Ponting CP: Comparison of the genomes of human and mouse lays the foundation of genome zoology. Hum Mol Genet 2003;12:701-709.

-28 Goossens GH: The role of adipose tissue dysfunction in the pathogenesis of obesity-related insulin resistance. Physiol Behav 2008;94:206-218.

29 Huneault L, Mathieu ME, Tremblay A: Globalization and modernization: an obesogenic combination. Obes Rev 2011;12:e64-72.

30 Kearney J: Food consumption trends and drivers. Phil Trans R Soc B 2010;365:2793-2807.

-31 Popkin, B: Does global obesity represent a global public health challenge? Am J Clin Nutr 2011;93:232-233. Woolf SH: The Meaning of translational research and why it matters. JAMA 2008;299:211-213.

-33 Ogilvie D, Craig P, Griffin S, Macintyre S, Wareham NJ: A translational framework for public health research. BMC Public Health 2009;9:116.

-34 Swinburn B, Gill T, Kumanyika S: Obesity prevention: a proposed framework for translating evidence into action. Obes Rev 2005;6:23-33.

35 Swinburn B, Egger G, Raza F: Dissecting obesogenic environments: the development and application of a framework for identifying and prioritizing environmental interventions for obesity. Prev Med 1999;29: 563-570.

-36 Kremers SPJ, de Bruijn GJ, Visscher TLS, van Mechelen W, de Vries NK, Brug J: Environmental influences on energy balance-related behaviors: a dual-process view. Int J Behav Nutr Phys Act 2006;3:9.

-37 Légaré F, Stacey D, Graham ID, et al: Advancing theories, models and measurement for an interprofessional approach to shared decision making in primary care: a study protocol. BMC Health Services Research 2008;8:2.

-38 Onis de M, Onyango AW, Borghi E, Siyam A, Nishida C, Siekmann J: Development of a WHO growth reference for school-aged children and adolescents. Bull WHO 2007;85:660-667.

39 Seidell J, et al, for Partnership Overweight Netherlands: Zorgstandaard Obesitas (in Dutch). Partnerschap Overgewicht Nederland, Zorgstandaard Obesitas. Amsterdam, November 2010.

40 NIH Publication: Clinical Guidelines on the Identification, Evaluation, and Treatment of Overweight and Obesity in Adults The Evidence Report. U.S. Department of Health and Human Services. Rockville, USA, NIH Publication No. 98-4083. September 1998.

-41 Iacobellis G, Ribaudo MC, Zappaterreno A, Iannucci CV, Leonetti F: Prevalence of uncomplicated obesity in an Italian obese population. Obes Res 2005;13:1116-1122.

-42 Seidell JC, Nooyens ACJ, Visscher TLS: Cost-effective measures to prevent obesity: epidemiological basis and appropriate target groups. Proc Nutr Soc 2005;64:1-5.

43 Baak van MA, Visscher TLS: Public health success in recent decades may be in danger if lifestyles of the elderly are neglected. Am J Clin Nutr 2006;84:1257-1258.

44 Visscher TLS, Rissanen A, Seidell JC, Heliövaara M, Knekt P, Reunanen A, Aromaa A: Obesity and unhealthy life years in adult Finns. An empirical approach. Arch Intern Med 2004;164:1413-1420.

-45 Swinburn BA, Sacks G, Hall KD, et al: The global obesity pandemic: shaped by global drivers and local environments. Lancet 2011;378:804-814.

46 Lobstein T, Dibb, S: Evidence of a possible link between obesogenic food advertising and child overweight. Obes Rev 2005;6:203-208.

47 Mil van M: Management of childhood obesity: lessons from a business case. Obes Facts 2009;2(suppl 2):51.

48 Stead M, Hastings G, McDermott L: The meaning, effectiveness and future of social marketing. Obes Rev 2007;8:189-193.

49 Nicolaou, M, Visscher T, Mavoa, H, Rasmussen F, Lissner L: Sociocultural, behaviour and economic factors in obesity prevention - a report from the pre-ICO meeting organised jointly by the Public Health and Prevention Task Force and Karolinska Institute on July 10, 2010 in Stockholm, Sweden. Obes Facts 2011;4: 249-253.

50 Jebb SA, Kopelman P, Butland B: Foresight 'Tackling Obesities: Future Choices' project. Obes Rev 2007;8 (suppl 1):vi-ix. 